\title{
Two methods for extraction of high-purity genomic DNA from mucoid Gram-negative bacteria
}

\author{
Xiao Xiao', Jingling Zhang ${ }^{1,2}$, Quanyi Zhang ${ }^{1}$, Li Wang ${ }^{1,2}$, Yafang Tan ${ }^{1}$, Zhaobiao Guo', \\ Ruifu Yang ${ }^{1}$, Jingfu Qiu ${ }^{2}$ and Dongsheng Zhou ${ }^{1 *}$ \\ ${ }^{1}$ State Key Laboratory of Pathogen and Biosecurity, Beijing Institute of Microbiology and Epidemiology, \\ Beijing 100071, China. \\ ${ }^{2}$ School of Public Health, Chongqing Medical University, Chongqing 400016, China.
}

Accepted 13 September, 2011

\begin{abstract}
Due to the production of abundant capsular polysaccharides and or exopolysaccharides, some bacteria form mucoid and opaque colonies on solid agar medium. Polysaccharides interfere with the isolation and characterization of DNA. Extraction of polysaccharide-free DNA from the mucoid bacteria is required for genetic and biochemical studies. In this study, mucoid Vibrio parahaemolyticus and Klebsiella pneumonia were used as model organisms for comparing the effectiveness of two DNA extraction methods. The two methods were proved reproducible and cost-effective for extracting highpurity genome DNA from mucoid bacteria for further applications.
\end{abstract}

Key words: Mucoid bacteria, Vibrio parahaemolyticus, Klebsiella pneumonia, DNA isolation, polysaccharides.

\section{INTRODUCTION}

Aside from having lipopolysaccharide as the major component of the outer membrane, some Gram-negative bacteria produce two other kinds of polysaccharides, namely, exopolysaccharide and capsular polysaccharide. These three kinds of polysaccharides are synthesized and modified by the enzymes encoded by different gene clusters in the genome. Exopolysaccharide, often constitute a loose slime outside the cells, is secreted by bacterial cells into the surrounding environment and is the major component of the intercellular matrix (Chen et al., 2010; Flemming and Wingender, 2010; Vu et al., 2009). Communities of bacterial cells encased in this matrix develop the biofilm that adheres to biotic or abiotic surfaces (Flemming and Wingender, 2010). Vibrio parahaemolyticus is one of the most important pathogens responsible for food-borne gastroenteritis, and is delivered to humans mainly through the consumption of contaminated raw or undercooked seafood (Yeung and Boor, 2004). V. parahaemolyticus expresses abundant exopolysaccharides and is able to form the biofilm

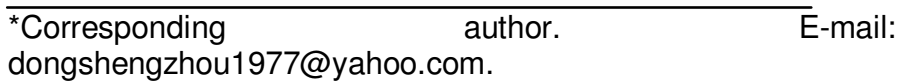

essential for its environmental survival and transmission by providing access to nutrients and protection from predators and adverse natural environmental conditions (Enos-Berlage et al., 2005; McCarter, 1999; Yildiz and Visick, 2009).

Capsular polysaccharide ( $\mathrm{K}$ antigen) constitute a dense, amorphous coat (called capsule) surrounding the whole cell, as a barrier between the cell wall and the environment (Roberts, 1996). Klebsiella pneumoniae is an opportunistic hospital-acquired pathogen that can cause urinary tract infections, pneumonia, septicemia, and community-acquired primary pyogenic liver abscess (Shu et al., 2009; Wu et al., 2009). Clinically, K. pneumoniae generally produces a large amount of capsule polysaccharide, making it a heavily encapsulated pathogen (Shu et al., 2009). Capsule polysaccharide synthesis is required for the virulence of $K$. pneumoniae (Cortes et al., 2002); encapsulated K. pneumoniae becomes invasive and causes septicemia and even liver abscess, due to its increased resistance to phagocytosis and complement-mediated killing (Cortes et al., 2002; Moranta et al., 2010). Capsule polysaccharide synthesis is also required for biofilm formation in K. pneumoniae, and this pathogen lacks the ability to produce exopolysaccharides (Balestrino et al., 2008). The 


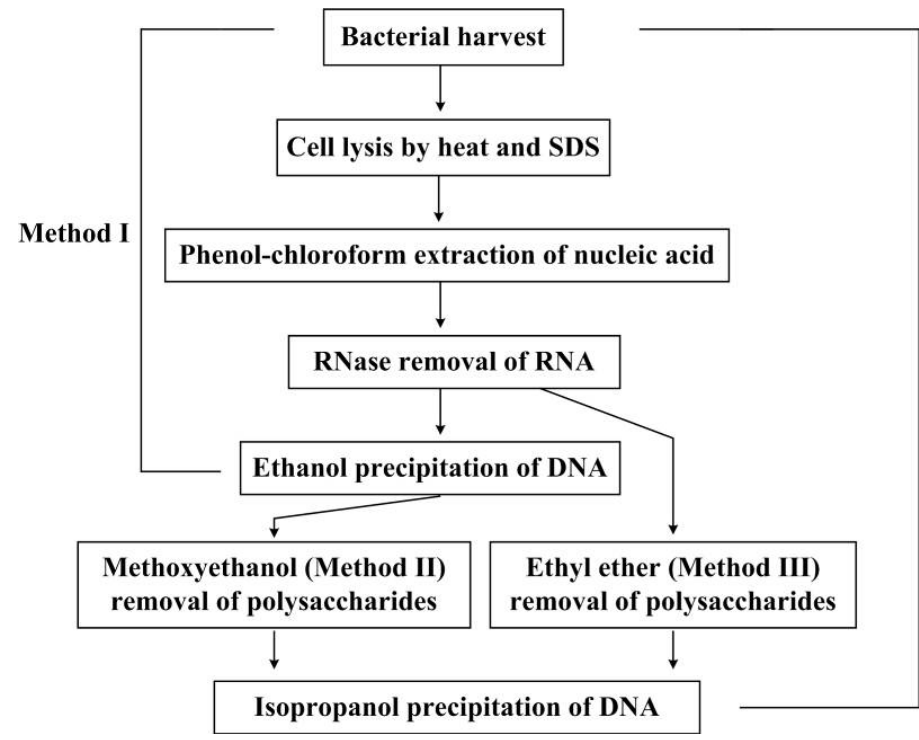

Method II or III

Figure 1. Flow-charts for different DNA isolation methods. The three DNA isolation methods (I, II, and III) used in this study. Method I is a traditional phenol/chloroform extraction approach. Method II and III were modified from Method I by introducing methoxyethanol and ethyl ether removal of polysaccharides, respectively.

formation of biofilm by K. pneumoniae on the host tissues inhibits the effectiveness of antibiotic treatment, protects against the host defense mechanisms, and facilitates the bacterial communication, leading to the expression of virulence determinants (Lavender et al., 2004).

Polysaccharides interfere with the isolation and characterization of DNA because (i) they interact with DNA to form highly viscous solutions; (ii) the DNA samples contaminated with polysaccharide are often unsuitable for restriction, Southern hybridization, and long-term storage; and (iii) they can cause anomalous reassociation kinetics (Crowley et al., 2003a; Crowley et al., 2003b; Lee et al., 2003; Sharma et al., 2002). Extraction of polysaccharide-free DNA from mucoid bacteria is required for genetic and biochemical studies.

In this study, mucoid $V$. parahaemolyticus and $K$. pneumoniae were used as model organisms, and two modified protocols for extraction of high-purity DNA were developed with removal of most of the contaminated polysaccharides in the DNA. These two methods should be suitable for genomic DNA isolation from other mucoid Gram-negative bacteria that produce high levels of polysaccharides.

\section{MATERIALS AND METHODS}

\section{Bacterial strains}

V. parahaemolyticus RIMD 2210633 is a pandemic strain isolated from a patient with traveler's diarrhea in Japan in 1996 (Chen et al., 2010; Nasu et al., 2000). K. pneumoniae NTUH-K2044 was isolated from a patient with liver abscess and meningitis in Taiwan (Wu et al., 2009). The genome sequences of these two strains have been determined (Makino et al., 2003; Wu et al., 2009). RIMD 2210633 expresses both exopolysaccharide and capsular polysaccharide (Chen et al., 2010; Nasu et al., 2000), whereas NTUH-K2044 is heavily encapsulated with capsular polysaccharide (K1 antigen) (Wu et al., 2009). Escherichia coli JM109 is a recombinant strain frequently used for laboratory studies.

\section{Bacterial growth and DNA isolation}

$K$. pneumoniae and E. coli were cultivated in Luria-Bertani (LB) broth at $37^{\circ} \mathrm{C}$, whereas $V$. parahaemolyticus was cultivated in LB broth containing $2 \% \mathrm{NaCl}$ at $37^{\circ} \mathrm{C}$. Bacterial cells were pelleted by centrifugation and the wet weight of each cell pellet was determined. Genomic DNA was isolated using the three methods (I, II, and III; Figure 1 for the flowchart, and the supplementary data for the detailed protocols). Experiments were performed in triplicate.

Method $\mathrm{I}$ is the traditional phenol or chloroform extraction approach modified from a previous study (Lee et al., 2003), and it was taken as a control in this study. Briefly, cells were pelleted from $200 \mathrm{ml}$ of bacterial culture with an $A_{600}$ value of 1.0 to 1.2, suspended in $10 \mathrm{ml}$ of SE buffer $(0.15 \mathrm{M} \mathrm{NaCl}, 0.1 \mathrm{M}$ EDTA, pH 8.0) containing $2 \%$ Sodium dodecyl sulfate (SDS), and incubated at $65^{\circ} \mathrm{C}$ for 30 to 60 min with intermittent shaking. One-half volume (5 $\mathrm{ml}$ ) of each of chloroform and Tris-saturated phenol were added, and then thoroughly mixed, followed by separation via centrifugation at $10,000 \times \mathrm{g}$ for $10 \mathrm{~min}$. The supernatant $(10 \mathrm{ml})$ was transferred into a new tube, and another extraction step with equal volume of chloroform was conducted. The nucleic acids in the aqueous phase were subjected to RNA digestion with $100 \mu \mathrm{g} / \mathrm{ml}$ RNase at $37^{\circ} \mathrm{C}$ for $30 \mathrm{~min}$, and then the DNA was precipitated by adding two volumes $(20 \mathrm{ml})$ of absolute ethanol, and the pellet collected on a glass rod was rinsed twice with $70 \%$ ethanol and dried. The dried DNA pellet was dissolved in $2 \mathrm{ml}$ of TE buffer (10 mM Tris, 1 mM EDTA, pH 8.0).

Method II is modified from Method I by introducing the methoxyethanol removal of polysaccharides. The 


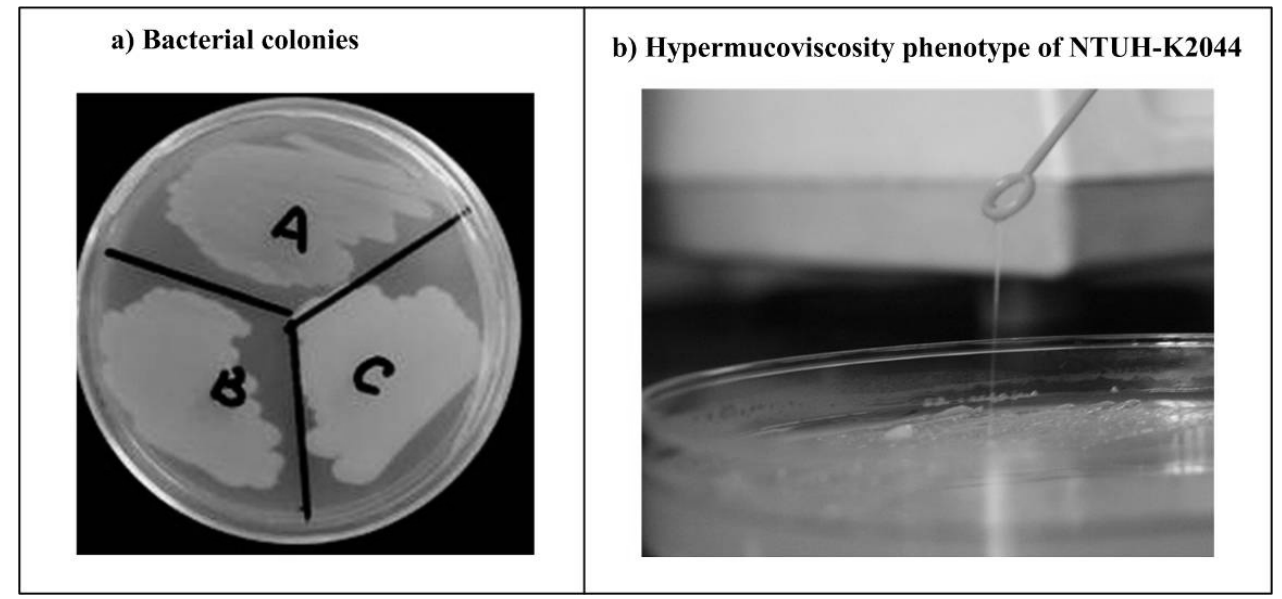

Figure 2. Mucoid phenotype of RIMD 2210633 and NTUH-K2044. Bacteria were grown on LB agar plate at $37^{\circ} \mathrm{C}$. a) NTUH-K2044 (B) and RIMD 2210633 (C) formed mucoid and opaque colonies on the solid agar media, whereas JM109 (A) produced non-mucoid and transparent ones. b) When the colonies of NTUH-K2044 were touched with a loop and the loop vertically lifted from the surface of the agar plate, the mucoid colonies adhered to the loop as it was lifted from the plate. NTUH-K2044 was thus considered to have the hypermucoviscosity phenotype (Yu et al., 2007), which was not observed in RIMD 2210633 and JM109.

ethanol-precipitated DNA pellet was dissolved in $5 \mathrm{ml}$ of TE. Equal volume $(5 \mathrm{ml})$ of $2.5 \mathrm{M}$ potassium phosphate $(\mathrm{pH} 7.6)$ was added and vortexes. Equal volume $(5 \mathrm{ml})$ of chilled methoxyethanol was added, vortexes, and centrifugated. The DNA in the clear supernatant $(10 \mathrm{ml})$ was precipitated with equal volume of isopropanol, followed by washing twice with $70 \%$ ethanol. The dried DNA pellet was dissolved in $2 \mathrm{ml}$ of TE.

Method III is modified from Method I by introducing the ethyl ether removal of polysaccharides. One-third volume (about $3 \mathrm{ml}$ ) of $5 \mathrm{M} \mathrm{NaCl}$ was added into the aqueous phase after RNA digestion, to a final $\mathrm{NaCl}$ concentration of about $1.2 \mathrm{M}$. Equal volume $(13 \mathrm{ml})$ of water-saturated ethyl ether was added, and then the phases were thoroughly mixed, followed by centrifugation at $10,000 \times \mathrm{g}$ for $10 \mathrm{~min}$. The aqueous phase was carefully transferred to a new tube. Further DNA precipitation, washing, and re-dissolving steps were as described in Method I.

\section{DNA quality assessment}

Using TE as the blank control, the optical absorbance values at wavelengths of 230,260 and $280 \mathrm{~nm}\left(A_{230}, A_{260}\right.$, and $A_{280}$, respectively), and the DNA concentration for each DNA sample were determined using a NanoDrop 1000 spectrophotometer (manufacturer and short address). The $A_{260} / A_{280}$ and $A_{260} / A_{230}$ ratios were calculated accordingly. Whole wavelength scanning of DNA samples were also conducted using NanoDrop 1000. The DNA samples were further analyzed by $0.7 \%$ agarose gel (Qbiogen, short address) electrophoresis with ethidium bromide staining, to determine DNA size and to assess RNA contamination.

\section{RESULTS AND DISCUSSION}

\section{Design of DNA isolation}

The DNA isolation method I is a typical phenol/chloroform extraction approach without specific polysaccharide removal procedures. Methods II and III were modified from Method I by introducing methoxyethanol and ethyl ether for removal of polysaccharides, respectively. These two polysaccharide removal approaches were originally established in plant or animal DNA isolation (Crowley et al., 2003a; Kirby, 1957).

The above three DNA isolation methods were tested with three Gram-negative bacterial strains, $V$. parahaemolyticus RIMD 2210633, K. pneumonia NTUHK2044, and E. coli JM109. RIMD 2210633 and NTUHK2044 formed mucoid and opaque colonies on solid agar medium (Figure 2a) due to the abundant production of capsular polysaccharides and or exopolysaccharides. Moreover, a string test (Pinsky et al., 2009; Yu et al., 2007) of the cultured colony (Figure $2 b$ ) showed that NTUH-K2044 had a hypermucoviscosity phenotype, that is; it grew into extremely sticky colonies when plated on agar with nutrient media. These results were consistent with previous observations for mucoid $V$. parahaemolyticus and K. pneumonia (Lam and Monteiro, 1984; McCarter, 1999; Pinsky et al., 2009; Yu et al., 2007). In contrast, the non-mucoid JM109 formed transparent colonies, and were used as the control in this study.

\section{DNA yield}

The yields of DNA obtained using the three methods were different, and those from Method I were the highest (Table 1). The addition of polysaccharide removal procedures in DNA isolation significantly reduced the 
Table 1. Comparison of different DNA isolation methods.

\begin{tabular}{|c|c|c|c|c|c|}
\hline Bacterium & Mucoid & DNA isolation method & DNA yield $^{\xi}$ & $\mathrm{OD}_{260} / \mathrm{OD}_{280}$ & $\mathrm{OD}_{260} / \mathrm{OD}_{230}$ \\
\hline \multirow{3}{*}{$\begin{array}{l}\text { Escherichia coli } \\
\text { JM109 }\end{array}$} & \multirow{3}{*}{ No } & $\mathrm{I}$ & $2.62 \pm 0.16$ & $1.91 \pm 0.01$ & $2.04 \pm 0.04$ \\
\hline & & II & $0.93 \pm 0.03$ & $1.87 \pm 0.01$ & $2.37 \pm 0.01$ \\
\hline & & III & $1.09 \pm 0.12$ & $1.84 \pm 0.00$ & $2.28 \pm 0.02$ \\
\hline \multirow{3}{*}{$\begin{array}{l}\text { Vibrio parahaemolyticus } \\
\text { RIMD } 2210633\end{array}$} & \multirow{3}{*}{ Yes } & I & $0.94 \pm 0.13$ & $1.91 \pm 0.02$ & $1.35 \pm 0.24$ \\
\hline & & II & $0.56 \pm 0.07$ & $1.85 \pm 0.02$ & $2.81 \pm 0.10$ \\
\hline & & III & $0.42 \pm 0.12$ & $1.84 \pm 0.01$ & $2.34 \pm 0.02$ \\
\hline \multirow{3}{*}{$\begin{array}{l}\text { Klebsiella pneumoniae } \\
\text { NTUH-K2044 }\end{array}$} & \multirow{3}{*}{ Yes $^{\&}$} & I & $1.56 \pm 0.45$ & $1.81 \pm 0.02$ & $0.71 \pm 0.04$ \\
\hline & & II & $1.03 \pm 0.06$ & $1.85 \pm 0.04$ & $2.27 \pm 0.10$ \\
\hline & & III & $0.61 \pm 0.14$ & $1.87 \pm 0.01$ & $2.14 \pm 0.03$ \\
\hline
\end{tabular}

For each strain, each of the three replicated DNA samples obtained through the three DNA isolation methods was diluted with TE to a final DNA concentration of $100 \mathrm{ng} / \mu \mathrm{l}$. The $A_{230}, A_{260}$, and $A_{280}$ values, as well as the DNA concentration of each diluted DNA sample were then determined using NanoDrop. Data are shown as mean \pm standard deviation. \&, hypermucoviscous $\xi$, mg of DNA per g (wet weight) of cell pellets.

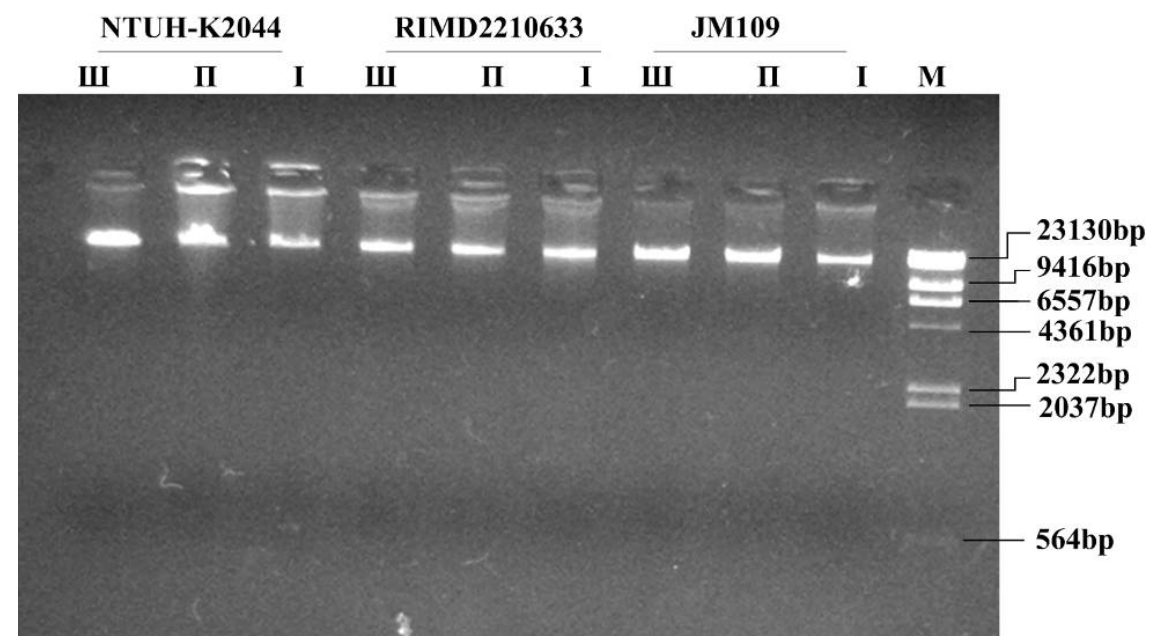

Figure 3. Agarose gel electrophoresis of DNA samples. For each strain, the three replicated DNA samples obtained through the three DNA isolation methods were pooled with equal quantity and diluted with TE to a final DNA concentration of $50 \mathrm{ng} / \mu \mathrm{l}$. The $150 \mathrm{ng}$ of DNA was run on a $0.7 \%$ agarose gel in $0.5 \times$ TBE buffer at a voltage of 8 to $10 \mathrm{~V} / \mathrm{cm}$. Gels were stained with ethidium bromide and visualized under UV light. DNA size marker III (manufacturer?) was run as control.

yields of DNA (Table 1).

\section{No RNA contamination and DNA degradation}

The gel electrophoresis assay (Figure 3 ) indicated that the bands of all the isolated DNA samples tested were sharp, and that no signs of RNA smears and degraded DNA were observed. These results confirmed that all the three methods gave reproducible yields of DNA without RNA contamination and DNA degradation for all three bacteria.

\section{No protein contamination}

The nitrogenous bases in DNA or RNA in the solution maximally absorb ultraviolet light at $260 \mathrm{~nm}$, whereas the amino acids with aromatic rings in proteins absorb light with absorbance maxima at $280 \mathrm{~nm}$. The DNA sample contaminated with proteins has an increased absorbance at $A_{280}$, and $A_{260} / A_{280}$ for the pure DNA fell between 1.8 and 2.0. In this study, the $A_{260} / A_{280}$ ratios were calculated for each DNA sample to evaluate the three DNA isolation methods (Table 1). All three methods yielded $A_{260} / A_{280}$ values between 1.8 and 2.0 for all the 3 bacteria, 


\section{Method I}

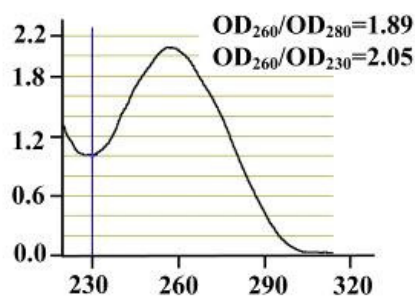

Method II

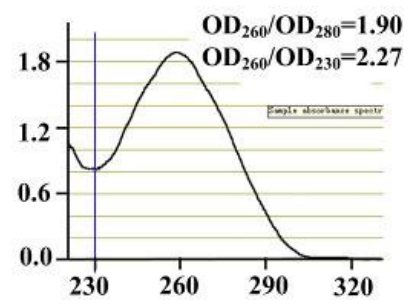

Method III

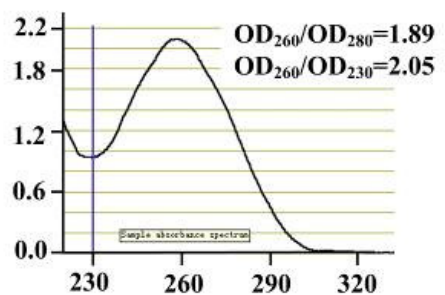

JM109

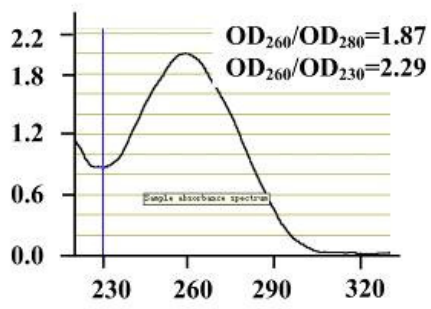

RIMD2210633
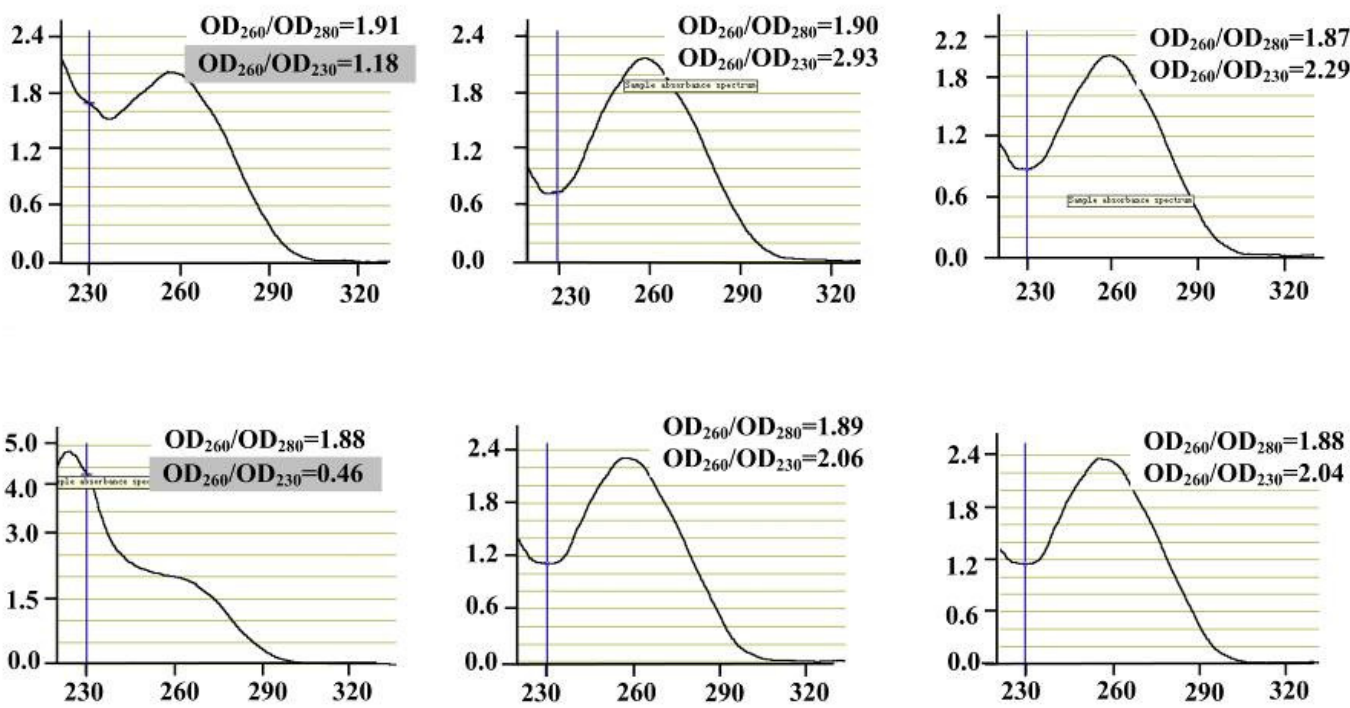

NTUH-K2044

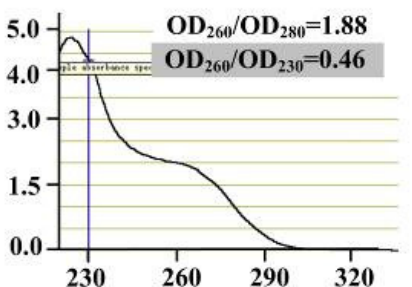

Figure 4. Wavelength scanning of DNA samples. For each strain, the three replicated DNA samples obtained through the three DNA isolation methods were pooled with equal quantity and diluted with TE to a final DNA concentration of $100 \mathrm{ng} / \mu \mathrm{l}$. Whole wavelength scanning of each pooled DNA sample was conducted with NanoDrop 1000.

indicating the relevant DNA samples were free of protein contamination.

\section{Removal of polysaccharide contamination}

Absorption at $230 \mathrm{~nm}$ in the DNA sample can be caused by contamination with carbohydrates, phenolate ions, thiocyanates, and other organic compounds. A pure DNA sample should yield an $A_{260} / A_{230}$ value $\geq 2$.0. Herein, the $A_{260} / A_{230}$ ratios were calculated for the DNA samples isolated with the three DNA isolation methods (Table 1). Methods II and III yielded $A_{260} / A_{230}$ values $\geq 2.0$ for all the three strains, but Method I yielded values $\geq 2.0$ for only non-mucoid JM109, but not mucoids RIMD 2210633 and NTUH-K2044. For the DNA samples isolated from RIMD 2210633 and NTUH-K2044 using Method I, the $A_{260} / A_{230}$ values were less than 1.4 , indicating a heavy contamination with polysaccharides.

In addition, the three replicated DNA samples isolated from each strain using each method were pooled and then subjected to whole wavelength scanning (Figure 4). This analysis depicted a single peak of absorbance at $280 \mathrm{~nm}$, as well as the $A_{260} / A_{280}$ and $A_{260} / A_{230}$ ratios for each pooled DNA sample, which further confirmed the above-disclosed efficiency of each DNA isolation method for each strain.

\section{Concluding remarks}

Method I work well on many non-mucoid Gram-negative bacteria including JM109 tested herein, but it does not work well on the two mucoid bacteria, $V$. parahaemolyticus and $K$. pneumoniae tested. This indicated that a specific polysaccharide removal design is essential for the extraction of high-purity genomic DNA from mucoid Gram-negative bacteria. Methods II and III were modified from Method I by introducing two different polysaccharide removal strategies, and both of them are proven reproducible and cost-effective for extraction of high-purity DNA from mucoid V. parahaemolyticus and 


\section{K. pneumoniae.}

As previously reported (Lambert, 1982), the pretreatment of $K$. pneumoniae cells with $50 \%(\mathrm{v} / \mathrm{v})$ dimethylsulfoxide before cell lysis minimizes the contact of polysaccharide with the DNA. Thus, it was performed to isolate DNA with negligible contamination of polysaccharide. However, when this method was used on NTUH-K2044, the cells could not essentially be pelleted after the dimethylsulfoxide treatment. When it was applied to RIMD 2210633, the $A_{260} / A_{230}$ ratios of DNA were less than 2.0, indicating its limited capacity to remove polysaccharides. Another method has been proposed to extract the genomic DNA of extracellular polysaccharide-producing Gram-negative bacteria (Chan and Goodwin, 1995), which was proven in this study to work well on NTUH-K2044 and RIMD 2210633. However, this method involves treatment with the hazardous chemical ethidium bromide.

In conclusion, two reproducible methods (Methods II and III) were established for extracting high-purity genomic DNA from mucoid Gram-negative bacteria. These two methods could also be applied to mucoid Gram-positive bacteria if lysozyme (e.g., using lysostaphin specific for Staphylococcus) was used in the cell lysis step. The low cost of this method makes it attractive for large-scale extraction of DNAs from mucoid bacteria.

\section{ACKNOWLEDGEMENTS}

The authors thank the National Natural Science Foundation of China (30871370), the National Basic Research Program of China (2009CB522604) for their financial support. They also thank professors Mitsuaki Nishibuchi from Kyoto University, and Jin-Town Wang from National Taiwan University for kindly providing the bacterial strains.

\section{REFERENCES}

Balestrino D, Ghigo JM, Charbonnel N, Haagensen JA, Forestier C (2008). The characterization of functions involved in the establishment and maturation of Klebsiella pneumoniae in vitro biofilm reveals dual roles for surface exopolysaccharides. Environ. Microbiol., 10: 685-701.

Chan JW, Goodwin PH (1995). Extraction of genomic DNA from extracellular polysaccharide-synthesizing gram-negative bacteria. Biotechniques, 18: 418-422.

Chen Y, Dai J, Morris JG, Jr., Johnson JA (2010). Genetic analysis of the capsule polysaccharide ( $\mathrm{K}$ antigen) and exopolysaccharide genes in pandemic Vibrio parahaemolyticus O3:K6. BMC Microbiol., 10: 274.

Cortes G, Borrell N, de Astorza B, Gomez C, Sauleda J, Alberti S (2002). Molecular analysis of the contribution of the capsular polysaccharide and the lipopolysaccharide $O$ side chain to the virulence of Klebsiella pneumoniae in a murine model of pneumonia. Infect. Immun., 70: 2583-2590.

Crowley TM, Muralitharan MS, Stevenson TW (2003a). An efficient protocol for genomic DNA extraction from citrus species. Plant Mol. Biol. Rep., 21: 177a-177g.
Crowley TM, Muralitharan MS, Stevenson TW (2003b). Isolating conifer DNA: A superior polysaccharide elimination method. Plant Mol. Biol. Rep., 21: 97a-97d.

Enos-Berlage JL, Guvener ZT, Keenan CE, McCarter LL (2005). Genetic determinants of biofilm development of opaque and translucent Vbrio parahaemolyticus. Mol. Microbiol., 55:1160-1182.

Flemming HC, Wingender $\mathrm{J}$ (2010). The biofilm matrix. Nat. Rev. Microbiol., 8: 623-633.

Kirby KS (1957). A new method for the isolation of deoxyribonucleic acids; evidence on the nature of bonds between deoxyribonucleic acid and protein. Biochem. J., 66: 495-504.

Lam S, Monteiro E (1984). Isolation of mucoid Vibrio parahaemolyticus strains. J. Clin. Microbiol., 19: 87-88.

Lambert KJ (1982). Pretreatment of cells of Klebsiella pneumoniae with $50 \%(\mathrm{v} / \mathrm{v})$ dimethylsulfoxide yields purified deoxyribonucleic acid of low polysaccharide content. Agric. Biol. Chem., 46: 3079-3080.

Lavender HF, Jagnow JR, Clegg S (2004). Biofilm formation in vitro and virulence in vivo of mutants of Klebsiella pneumoniae. Infect. Immun., 72: 4888-4890.

Lee YK, Kim HW, Liu CL, Lee HK (2003). A simple method for DNA extraction from marine bacteria that produce extracellular materials. J. Microbiol. Methods, 52: 245-250.

Makino K, Oshima K, Kurokawa K, Yokoyama K, Uda T, Tagomori K, lijima Y, Najima M, Nakano M, Yamashita A, Kubota Y, Kimura S, Yasunaga T, Honda T, Shinagawa H, Hattori M, lida T (2003). Genome sequence of Vibrio parahaemolyticus: A pathogenic mechanism distinct from that of $v$ cholerae. Lancet, 361: 743-749.

McCarter L (1999). The multiple identities of Vibrio parahaemolyticus. J. Mol. Microbiol. Biotechnol., 1: 51-57.

Moranta D, Regueiro V, March C, Llobet E, Margareto J, Larrate E, Garmendia J, Bengoechea JA (2010). Klebsiella pneumoniae capsule polysaccharide impedes the expression of beta-defensins by airway epithelial cells. Infect. Immun., 78: 1135-1146.

Nasu H, lida T, Sugahara T, Yamaichi Y, Park KS, Yokoyama K, Makino $\mathrm{K}$, Shinagawa H, Honda T (2000). A filamentous phage associated with recent pandemic Vibrio parahaemolyticus O3:K6 strains. J. Clin. Microbiol., 38: 2156-2161.

Pinsky BA, Baron EJ, Janda JM, Banaei N (2009). Bartholin's abscess caused by hypermucoviscous Klebsiella pneumoniae. J. Med. Microbiol., 58: 671-673.

Roberts IS (1996). The biochemistry and genetics of capsular polysaccharide production in bacteria. Annu. Rev. Microbiol., 50: 285 315.

Sharma AD, Gill PK, Singh P (2002). DNA isolation from dry and fresh samples of polysaccharide-rich plants. Plant Mol. Biol. Rep., 20: 415a-415f.

Shu HY, Fung CP, Liu YM, Wu KM, Chen YT, Li LH, Liu TT, Kirby R, Tsai SF (2009). Genetic diversity of capsular polysaccharide biosynthesis in Klebsiella pneumoniae clinical isolates. Microbiol., 155: 4170-4183.

Vu B, Chen M, Crawford RJ, Ivanova EP (2009). Bacterial extracellular polysaccharides involved in biofilm formation. Molecules, 14: 25352554.

Wu KM, Li LH, Yan JJ, Tsao N, Liao TL, Tsai HC, Fung CP, Chen HJ, Liu YM, Wang JT, Fang CT, Chang SC, Shu HY, Liu TT, Chen YT, Shiau YR, Lauderdale TL, Su IJ, Kirby R, Tsai SF (2009). Genome sequencing and comparative analysis of Klebsiella pneumoniae NTUH-K2044, a strain causing liver abscess and meningitis. J. Bacteriol., 191: 4492-4501.

Yeung PS, Boor KJ (2004). Epidemiology, pathogenesis, and prevention of foodborne Vibrio parahaemolyticus infections. Foodborne Pathog. Dis., 1: 74-88.

Yildiz FH, Visick KL (2009). Vibrio biofilms: So much the same yet so different. Trends Microbiol., 17: 109-118.

Yu VL, Hansen DS, Ko WC, Sagnimeni A, Klugman KP, von Gottberg A, Goossens H, Wagener MM, Benedi VJ (2007). Virulence characteristics of Klebsiella and clinical manifestations of $\mathrm{K}$. pneumoniae bloodstream infections. Emerg. Infect. Dis., 13: 986-993. 